\title{
Āta: An Indigenous Knowledge Based Pedagogical Approach to Teaching
}

\author{
Huhana Forsyth \\ EDENZ Colleges, New Zealand
}

Copyright $\bigcirc 2017$ by authors, all rights reserved. Authors agree that this article remains permanently open access under the terms of the Creative Commons Attribution License 4.0 International License

\begin{abstract}
Western education theory and philosophy as the domain of the dominant pedagogy forms the basis of the New Zealand education system. Although the current form of education is reflective of the dominant cultures ideologies and philosophies it does not always serve the interests of all students. The philosophy of Āta offers an indigenous knowledge based pedagogical approach to teaching that has the potential to not only transform the learning experience of all students, but also provide teachers with a theory of best practice that is holistic and relational.
\end{abstract}

Keywords Indigenous Knowledge, Education, Teaching Pedagogy, Philosophy

\section{Introduction}

Aotearoa/New Zealand is blessed with a unique culture, the culture of tangata whenua (people of the land), Te Iwi Māori (Māori tribes), who preserve and practice a form of knowledge that if treated correctly, offers pedagogical approaches to teaching and learning that can uplift and enlighten the education environment. Āta is firmly posited within that source of knowledge and is an integral part of Te Ao Māori (the Māori world view), a 'take pū' (a base principle intrinsic of Te Ao Maori) [1] and is considered 'a vital cultural tool created to shape and guide understandings of relationships and well-being'.

The philosophy of Āta is grounded in the principle of reciprocity and is focused on growing respectful relations. Working with Āta becomes a journey that is guided by the philosophy itself, and Āta in practice becomes a way of being rather than a way of doing. Understanding A ta is essential to maintain the cultural integrity of the philosophy. Therefore we begin by introducing Âta, considering the origins and connections it has to accord it with the same respect that is an intrinsic part of the philosophy. The practical applications of the philosophy are considered along with examples of Āta as a pedagogical approach to inter-relational teaching practice. Following discussion on the role of reflective practice in working with Āta, the way in which the philosophy enhances learning is demonstrated through evidence based practical examples.

While the philosophy of Āta is firmly entrenched in the culture of Te Iwi Māori, the transformative nature of Āta is available to all practitioners who would work with respectful acknowledgement of its origins.

\section{The Philosophy of Āta}

While research and writing on the subject may be relatively new, the philosophy of Āta is not a new concept. A literal translation of Āta is 'with care, 'with deliberation'. The notion of respect is central to the philosophy of Āta, and as a pedagogical approach to teaching Āta focuses on growing respectful relationships. The choice of the word growing is both deliberate and significant, and is indicative of the gentle, holistic, nurturing aspect of the Āta philosophy. Pohatu [2] expands on the phrase respectful relationships in the following way:

Respectful relationships with its strategies and disciplines are located within understandings of the phrases, 'respect of', 'respect for', 'respect with', 'respect by', and 'respect through'. Within every context therefore, fundamental questions must be posed, such as, 'what should we have respect for?' 'Why should we consider respect?', and 'how would we construct and apply respect here?' These questions frame and reflect an ongoing determination to 'do our best'. As these are incorporated into our relationships and activities, so do they have the chance to become vigilant participants in our daily life.

The notion of respect is a significant aspect when developing relational teaching practices and the questions posed by Pohatu [2] require reflective deliberation. To assist teachers in answering these questions surrounding respect, a set of guiding principles can be found in the philosophy of Āta. 


\section{Guiding Principles}

In education contexts, exercising the principles of Āta in every action undertaken strengthens and develops the integrity of both the 'self' and the 'other' in any given relationship [3,4]. Pohatu [2] reminds us 'the pursuit of integrity and respectfulness in relationships and their boundaries is fundamental'. This can be achieved through diligently considering and applying the following actions as described by Pohatu [1]:

- Kia tôtika: To be correct. To aspire towards standards of quality.

- Kia tika tonu: To act responsibly, to respect the integrity of others.

- Kia pai: To be careful. To be considerate and deliberate.

- Kia rangatira te mahi: To act with utmost integrity, to consider the unique positions of others.

- Kia tūpato: To carefully consider the consequences, to ensure integrity in all actions.

Adopting these principles into practice is relatively simple as Āta provides the tools required through the actioning of specific Āta phrases. And yet the very nature of Āta requires reflection, diligence, and continued effort. Āta focuses on growing respectful relationships, it accords space and time, and it demands effort and energy. To assist teachers in following the principles of Āta, the following set of phrases have been developed specifically for education contexts [5] based on those espoused by Pōhatu [1].

- Âta-haere: To be intentional and approach reflectively;

- Āta-whakarongo: To listen with reflective deliberation;

- $\quad \overline{t a-n o h o: ~ T o ~ g i v e ~ q u a l i t y ~ t i m e ~ t o ~ b e ~ w i t h ~ p e o p l e ~ a n d ~}$ their issues;

- Āta-whakaaro: To think with deliberation, considering possibilities;

- Âta-korero: To communicate and speak with clarity.

When considering these phrases in more depth the guiding principles of Āta begin to take on a more applicable form, a more familiar shape and a stronger resonance. For example, in the classroom, Âta-haere would be translated into an intentional, careful, and reflective approach to content, delivery, growth towards understanding, and physical movement. This demands deep and actioned respect by all involved parties, requiring an awareness of relationships, boundaries, and cultural requirements. Āta-whakarongo, to listen with reflective deliberation, is indicative of the holistic nature of the Āta philosophy, according time, space, and validity to the speaker and allowing open communication from the heart, mind, and soul. Āta-noho guides actions and interactions in the classroom dictating 'quality time and space' which goes hand in hand with Āta-haere. $\bar{A}$ ta-whakaaro and Āta-korero combine to ensure words are spoken that have been given careful deliberation and chosen through thoughtful reflection. The phrases can be further examined to reveal meanings that are intrinsically imbedded within the essence of Āta. Phrases such as 'quality time and space', when considered in relation to Āta, reveal a meaning that is not about a measure in the sense that 'quality' is measurable, but is about a way of being in the 'space and time' in the same way as 'Kia tōtika -to be correct' is about a way of being, of aspiring towards certain standards. In this way, Âta challenges us to reconsider the meaning of words and to think about words from a cultural perspective rather than from a definitive perspective, that is to say, considering $\bar{A}$ ta as it sits within a cultural context rather than just the direct translation and definition of the word.

Just as the philosophy of Āta is interconnected with all Māori philosophy, and is part of Te Ao Māori (the Māori world view), so too are the individual principles of the philosophy connected to each other and to the philosophy as a whole. Working with Āta one needs to develop an awareness of the different signposts of relationships outlined in the philosophy by understanding the connections that exist between the Äta phrases, the knowledge embedded in each of these phrases, and how this knowledge is valued and deliberately instructed, monitored, and corrected (Āta-tohutohu).

A key point of consideration is an awareness that these separate units of Āta are cohesively integrated towards a holistic whole. That is, a whole that is determined and explained by the sum of its component parts and the inter-connectedness of those same parts. Interacting with other 'take pu' with their unique filtering processes, creates further opportunities for the holistic and multi-dimensional nature of Āta to be understood and provides the chance to experience its 'renewing' possibilities [1]. In other words, when our relational experiences are explicitly fleshed out, when we consciously action the Āta phrases in our teaching practice, the literal translation of Āta meaning 'with care, with deliberation', becomes evidenced.

\section{Maintaining Cultural Integrity}

The philosophy of Āta is an integral part of Te Ao Māori (the Māori world view). To fully understand the philosophy, to consider and apply in within the paradigms of education, it is essential to acknowledge the depth of knowledge contained in the philosophy and to do so with cultural integrity. A ta is a living philosophy and to embrace it is to add to its life force, to acknowledge and enhance its mauri (life essence).

When considering a philosophical approach that is founded on indigenous knowledge it is imperative we strive to maintain cultural integrity in all our actions. From a Māori worldview, Āta has its own life force, it has 'mauri' (a life essence). The concept of mauri, as with all aspects of Te Ao Māori, cannot exist in isolation [6]. There is an interconnectedness that permeates to the heart of every part of being Māori. Mauri denotes existence, and it signals 
obligations of each new time to its past and future. Therefor the philosophy of Āta is a living concept, a knowledge base with its own mauri. In doing so acknowledgment must be made that along with a present existence, and a future direction, it has a past, a whakapapa (a genealogical line of descent).

Recognising these things creates an entirely different position to the worldview that sees a philosophical concept as a disconnected idea, or a theory. Along with this comes an obligation to approach it with respect and to act with integrity and sincerity. We can't just choose to use this as a convenient model without acknowledging and respecting the cultural integrity of its origins. Cultural integrity in this instance demands consideration of Āta as being intertwined with universal Māori knowledge before attempting to extract it as a separate identity. Therefore, any investigation of Āta must accord the knowledge it conveys with respect, as Āta is part of Māori worldviews and unique bodies of Māori cultural knowledge with their wisdoms, depths of definition and application are privileged, having been tested over generations, in the full range of human endeavor [1]. Only by first considering Āta as a component in Māori worldviews, can its cultural integrity be maintained, allowing it then to be moved into other contexts, to re-interpret, re-articulate, and re-apply it. This serves as a reminder that considering Māori worldviews requires constantly seeking to acknowledge the integrity and respectfulness within the legacies of others. In doing this, the true cultural shape and nature of Āta is revealed.

To demonstrate the need for maintaining cultural integrity when applying Āta in teaching, consider the phrase Āta haere. The literal translation of Āta is 'with care, 'with deliberation' and the literal meaning of haere is commonly explained as 'to go'. Yet the word haere also means to move, to become, to be diffused, and to indicate progressive change, which shows that the phrase 'Āta haere' has a multiplicity of meanings that are dependent upon and inter-connected to time, space, context, and abstract constructs. Therefore, to maintain the cultural integrity of the phrase the complexity of it must be acknowledged and respected. In so doing, 'Āta haere' moves away from the literal translation of 'to move with care and deliberation, and becomes a way of being, a way of 'presencing' the teaching self in relation to the class, and a way of moving the learning forward.

When using Āta as a pedagogical approach the philosophy itself guides the direction travelled and so in essence the journey becomes one with Āta, not one into Āta. Each step taken, each direction turned in, contributes to the whakapapa of Āta and adds to its mauri. This re-iterates the existence of mauri within the philosophy, and demonstrates the inter-connectedness of Māori worldviews. The most significant aspect of this is that it does not set humankind aside. Although the dominant pedagogy may perceive there is some form of connection in existence, being separate to, not inclusive of, humankind. Māori whakapapa shows that not only is te tangata (humankind) a part of the world, part of the vast and unending universe, but also is essentially related to it. This belief is a guiding principle in every action, every thought, and every relationship formed as one moves through the world [7]. One develops, and is constantly transformed, by relationships, relationships with the world through one's connection to all living things. This requires an acute awareness that things connected to are in turn transformed, and signals a need for caution, a need to act with clear and deliberate intentions. The philosophy of Āta offers a path to follow that guarantees all actions are legitimate and following the principles of Āta in those actions, ensures cultural integrity is maintained.

\section{5. Āta: An Inter-Relational Holistic Pedagogical Approach}

Āta in practice is about growing respectful relationships that look to understand and acknowledge the inter-related, inter-connected whole. Teacher educator Parker Palmer [8], stated that inter-relational holistic teaching practice begins with teaching from the authentic self and to understand that he suggested we ask 'who is the self that teaches? Palmer believed that reflecting on the teaching self enables expressions of the self evidenced by identity and integrity. Identity in this context means acknowledgement of the forces that make you who you are, the self; while integrity speaks to what makes you whole, who I am. Expanding on this, Intrator [9] expresses the idea that teachers:

Act with integrity when the source of our actions flow from our deepest beliefs and principles. When our actions align with what we care about and emanate from the source of our moral commitments, we act with integrity. When we are compelled to act in ways contrary to our principles, our sense is deformed and diminished.

Engaging in teaching practice based on the principles of $\bar{A}$ ta, and through internalising each Āta phrase, the identity and integrity of the teacher is evidenced. A teacher who listens with reflective deliberation (Āta-whakarongo), who, with deliberate intent sets aside quality time to be with students (Āta-noho), and who acts responsibly and with integrity (kia tika tonu), presents as an inter-relational holistic teaching self. Through these relational encounters the teaching self is further defined and shaped. According to Palmer [8] what sets great teachers apart as they relate with their students is the essence of their being, who they are. It is not what they teach or how the content is taught, what is of primary importance is how they connect with you to value your own being and who you are - yourself [3].

When considering relational connectedness in teaching and learning, Gibbs [10], argued that 'learning and teaching is both about, and involves, people. Becoming and being a teacher, therefore, is intimately human'. Extending on this, Gibbs [10] was concerned that teachers, within the context of 
teaching and learning, are often denied opportunities to develop the capacity for relational knowing. What is required is an alternative to the dominant pedagogical approach that provides a base for developing relational connectedness. Āta provides an opportunity to reconsider what teaching and learning is all about - relational connectedness [11]. Palmer [8] espoused that teaching and learning is enriched by the presencing of self and the recognition of the other through sincere relational engagement. Teaching under the philosophy of Âta presenting of self becomes not only possible, but inevitable. According to Kung [3];

When teachers act based on kia rangatira te mahi, the position and integrity of students are taken into deep consideration. Teaching and learning is then an empowering process with rich transformative potentials. Students who feel empowered are able to fly up with wings like eagles and take flight. In this instance...the whole teacher is drawn into a relationship with their students. When connections are established, teaching is then a gifting of the teacher's self, a relational engagement.

Kung's [3] reference to 'the whole teacher' is interesting as it opens the dialogue on the role of the teacher in holistic teaching practice. In general terms, holistic practice has focused on considering the 'whole' student and yet if the engagement is to be relational and respectful, the teacher must be included as an integral part of the relationship. Buber [12] affirms that teaching is an encounter and a dialogue, and dialogue is a relational connection. It is the nature of this relationship that either forms or deforms the learning experience. Āta not only allows for relational dialogue, it also opens up spaces for considering dialogue from a holistic perspective, and significantly does so from a perspective outside of dominant pedagogical practices. Typically, the 'Anglo process of categorization lends itself to a more linear approach.... what is required is a more holistic approach' [13] and this is important to consider when working with indigenous and minority group learners. From an indigenous perspective, the 'need to understand the whole is more important than understanding the parts' [14] and with principles firmly imbedded in Indigenous knowledge, Āta offers a pedagogical approach that is both holistic and relational.

For teachers to be able to engage in holistic based relational practice, they must be able to develop an awareness of their teaching self. Kottler and Zehm [15] refer to this as 'internal human resources' that can be called on to empower the teaching. Including this human dimension in teaching opens a way of forming connections through the inner being of the teacher, the subject taught and the presence that holds the interaction together, a relational connectedness that strengthens the learning [3].

When deliberating on relational connectedness in teaching and environments, Gibbs [11] concludes that 'learning and teaching is both about, and involves, people. Therefore, relational connectedness in teaching and learning is enriched by the presencing of self and the recognition of the other [16]. Âta opens a door to revisit teaching and learning as an act of holistic inter-relational connectedness. For example, when teachers act based on kia rangatira te mahi, the integrity and position of the students must be taken into deep consideration. In this way, teaching and learning becomes an empowering process with rich transformative potentials [3] and the holistic nature of Āta is revealed as the whole teacher is drawn into a relationship with their students. Working under the principles of Āta, the teacher presence is relational in nature with each member in the teaching/learning environment being acknowledged, valued, and empowered holistically, both as an individual and as a part of the whole. Âta provides an enriching and empowering environment that is holistic and inter-relational.

\section{6. Āta: Reflective Practice}

Me āta titiro ki muri kia mōhio ai koe tou ake āhuatanga nāianei kai kite koe hoki te ara tika e ngā ra e heke mai. The English translation of this well-known whakataukii, look to the past so you will know the shape of your present and the correct path for the future, indicates that reflective practice is not a new concept for Te Iwi Māori. Working under the principles of Âta teachers and learners need to develop reflective skills as the principles of Āta are based on developing the skills of the reflective practitioner. Actioning the principles of Āta demands reflection to guarantee quality standards are upheld in each step of the process. The very translation of the word Āta, with care, with deliberation, is indicative of the level of reflection and critical analysis needed to operate under the principles of Āta [17]. The importance of careful consideration, critical reflection, and deliberate action are underlined in the need for constant 'pausing', a notion that is implicit in Âta [1].

This notion of pausing calls for us to deliberate with care and gentleness as we develop relationships. This is strongly evident in all the Āta phrases. For example, Āta whakarongo requires us to pause to listen, to deliberate and listen with care. Listening with careful, reflective deliberation signals the elements of trust, integrity and respectfulness of what is being shared. Such thoughtful consideration or reflection is the careful analysis not only of actions or decisions, but also of the processes followed in accomplishing them. These processes are expressed through relationships and connections and Āta spells out the action verbs that help guard and preserve student-teacher relationships. For example, Āta-haere informs of the need for an intentional and reflective approach in all things, and Āta-noho reminds us of the need to allow quality time and space to be with people and their issues. Through the action verbs, Āta offers a way of negotiating relationship boundaries that develop safe space and respectful connections grounded on constant reflection. 
Reflection is a critical dimension of what it means to be an effective teacher $[18,19]$. Becoming a reflective practitioner is not a simple task that is easily accomplished [20]. Reflection is an extremely complex and demanding process that does not come naturally to teachers [3]. However, with the notion of pausing, and action phrases based on careful deliberation, Āta opens an avenue to ground reflective practice. Because Āta is reflective in nature, working under the principles of Āta not only requires reflective practice skills, it also provides a way for teachers to develop and enhancing those skills.

\section{7. Āta in Practice}

Working under the principles of Āta demands effort and energy. Âta is a complex, inter-connected cultural approach firmly posited within an indigenous knowledge base. And yet it also has clear constituents and guidelines that make working under the principles a relatively simple concept, allowing integration of the philosophy of Āta into teaching professional practice. Following the principles enables teachers to develop and enhance relationships in any classroom setting with a variety of individual groups.

The transformative potential of Āta was evidenced in a study undertaken in 2005 [5]. Using teaching based on Āta principles a multi-ethnic group of 82 , were selected. The group were first semester, first year students on an education undergraduate program. The students were aware they were participating in a study but were not introduced to the philosophy as such until after the completion of the data gathering process. Essentially the study was focused on the teaching practice. However, within three weeks, the students were observed to be demonstrating Āta principles in their approach to the learning.

The inter-relational holistic teaching and learning that developed within the group was noticeably greater than that of previous groups. The principles of Āta became firmly embedded in the classroom environment and became a part of the ritual of the group. Āta-korero, Āta-whakarongo, Ata-noho and Āta-haere were used to accord respect to each member of the group and place value on all members.

The notion of separation between teacher and student was minimised and the group functioned as a single unit, while still allowing for individual recognition and validation. Once the group became familiar with following the principles of the philosophy of Âta, the integrity of each member was acknowledged and maintained. Viewpoints were exchanged openly, and without fear, and mutual respect was strongly evident within the group. This was evidenced in many ways, ranging from quiet respectful listening whenever anyone was speaking, to actual spoken statements such as "I really respect your contribution to our discussion" and "I had never considered that point of view before, it is so important".

Findings from the study indicated the relationships that had been developed contributed significantly to the success of the group, both academically and personally [5] and this was not restricted to the paper involved in the study. The relationships that developed were carried through to other papers and were observed by all teaching staff associated with the group. Many of the students who took part in the study have gone on to incorporate the principles of Âta into their own teaching practice and some are now teaching it as a philosophical approach.

The study also found that although Āta is an Indigenous based approach, application of Âta is not restricted to Indigenous contexts. The group of students involved in the study, were predominantly of European ethnicity and the teaching context was one of the dominant pedagogical group of Aotearoa New Zealand. The classroom was a tiered lecture theater and the lesson format was a lecture followed by a tutorial. The results of the study showed that it is possible to apply the principles of Āta in any teaching environment and that inter-relational teaching can occur with large groups in a lecture theatre and that increased student engagement is strongly evident. Educators and researchers recognize the benefits of reflective teaching and relationality in teaching, and have looked to find an approach that could be applied in a variety of contexts. Āta provides a basis for teachers to frame their own practice in a reflective and relational way.

Incorporating the principles of Āta into teaching practice is relatively simple, yet the very nature of Āta requires constant reflection, diligence, and continued effort as the group, and individuals within the group are transformed. When working with Âta, the teaching professional must continually revisit the principles to uphold the integrity of the relationship and maintain the cultural integrity of the philosophy. Through deliberate reflection and as teaching professionals develop an understanding of, and ability to apply the principles of Āta in daily practice, the process will become a part of the overall philosophy of the teaching/learning environment. The principles are individually extremely powerful, yet, when combined as an overall philosophy their true worth is extensive. Combining Âta and reflective practice enables a professional approach to teaching maintaining a humanistic base in teaching and learning interactions.

To experience the transformative potentials of Āta requires a shift in teachers' attitudes and mind-sets with active, conscious, reflective deliberation. Teaching under the principles of Āta entering, maintaining and exiting all levels of relationships becomes as important in the classroom as the subject being taught. This moves teaching away for being a knowledge transferring exercise, and calls for teachers to act with care and deliberate intent to honour the other and the relationship that is formed. Herein lies the challenge to those who see the transformative strengths of this promising philosophy for teacher education. The Āta philosophy underpins the development of quality relationships that can positively move us in the right direction.

Developing teaching practice based on the inter-relational 
nature of Āta provides teachers with a basis to work from and to return to. The philosophy of Āta has the potential to guide, inform, and shape current teaching practice and teaching under the principles of Āta enhances the teaching learning environment [5]. Teaching professionals need to develop the different signposts of relationships outlined in the philosophy by understanding the connections that exist between the Āta phrases, the knowledge embedded in each of these phrases, and how this grounded knowledge is valued and deliberately instructed, monitored, and corrected (Āta-tohutohu) [3].

The practical applications of developing a teaching philosophy based on the principles of Āta are immense. According to Gay, [4] the 'interactions between students and teachers as well as among students in the classroom are frequently identified as the actual sites where learning success or failure is determined'. The study referred to above demonstrated that the dynamics of a group of new students can be enhanced by following the principles of Āta. As teacher educators we need to challenge students to articulate, confront, and reconstruct their teaching self as they peel back each layer of their practice, diving deep into their practice to reflect on how they have developed respectful relationships that draw on the transformative potential of Āta, and the relationships that are developed and nurtured in the learning environment contribute to the success of individual members of the group and the group as a whole. Significantly, the study also found that true relational teaching practice can be developed with large and diverse student groups in a variety of teaching spaces, indicating that holistic inter-relational practice is not restricted to 'small, intimate' settings. According each individual member due respect, space, and time, and validating the knowledge they as an individual bring to the group is a humanistic approach that emerges from working within the principles of Āta allowing for transformative relationships to take place. Âta also provides teachers with a safe, ethical approach to engaging in meaningful relationships that enhance the learning, while maintaining standards of professionalism.

While the philosophy of Āta is firmly entrenched in the culture of Te Iwi Māori, the application of the Āta principles is not restricted to any given ethnicity. Acknowledging the cultural integrity of Āta allows the development a framework which will give teaching professionals a deliberate and intentional base that can be actioned and modeled for all parties to function together in meaningful, respectful relationships. Âta provides an opportunity to integrate a truly bi-cultural teaching model that will guide and inform professionals working in the education arena.

\section{Conclusions}

$\bar{A}$ ta is considered a vital cultural tool created to shape and guide understandings of relationships and well-being. The constituents of Āta are milestones to help practitioners walk the complex, idiosyncratic world of teaching. Each Āta phrase prepares educators and student teachers to manage the complexities of relationships at all levels. Āta sets out the platform of how to establish, maintain and exit a relationship without harming the identity and integrity of the other person. They are relational rules of engagement that delineate the boundaries of acceptable, respectful relationships. Āta offers educators the opportunity to ground their practice on a theoretical framework that espouses respectful, meaningful and sincere relationships, the explicit call of Āta through reflective deliberations.

\section{REFERENCES}

[1] Pōhatu, T. W. (1994). I Tipu Ai Tatau i nga Turi O O Tatau Matua Tipuna, unpublished M.ED. Thesis, Auckland University.

[2] Pōhatu, T. (2004). Maori Worldviews: Source of innovative social work choices. He Komako.

[3] Forsyth, H \& Kung, N. (2007). Ata: A philosophy for relational teaching. New Zealand Journal of Educational Studies, Vol. 42, No. 1/2, 2007: 5-15.

[4] Gay, G. (2000). Culturally Responsive Teaching: Theory, Research, and Practice. Teachers College Press, New York, NY

[5] Palmer, P. J. (1993). To know as we are known: education as a spiritual journey (1st ed.). San Francisco: Harper.

[6] Forsyth, H. (2006). Āta: A theoretical base for best practice in teaching. Unpublished Master of Education Thesis. Auckland university of Technology.

[7] King, M. (1994). Te Ao Hurihuri (Ed) Reed: Auckland, NZ

[8] Leaf, G. (2014). Personal communication: AUT University, Auckland, NZ

[9] Palmer, P. J. (1998). The courage to teach: exploring the inner landscape of a teacher's life (1st ed.). San Francisco: Jossey-Bass.

[10] Intrator, S. M. (2002). Stories of the courage to teach: honoring the teacher's heart (1st ed.). San Francisco: Jossey-Bass.

[11] Gibbs, C. (2005). Becoming and being teacher: The formation of authentic identity through relational connectedness. Auckland, New Zealand: School of Education, Auckland University of Technology.

[12] Gibbs, C. (2006). To be a Teacher: Journeys Towards Authenticity. Pearson: Auckland, NZ

[13] Yoshida, A. (2002). Martin Buber: Education as holistic encounter and dialogue. In J. P. Miller \& Y. Nakagawa (Eds.), Nurturing our wholeness: perspectives on spirituality in education.

[14] Newman, J. (1991). Interwoven conversations: Learning and teaching through critical reflection. Toronto: Heineman.

[15] Pewewardy, C. (2002). Learning styles of American Indian/Alaska Native students: A review of the literature and implications for practice. Journal of American Indian Education. Vol. 41, No. 3, 2002: 3-81 
[16] Kottler, J., \& Zehm, S. (2000). On Being a Teacher. Corwin Press; Thousand Oaks, CA

[17] Palmer, P. J. (2003). Teaching with heart and soul: Reflections on spirituality in teacher education. Journal of Teacher Education, 54(5), 376-385.

[18] Forsyth, H., \& Kung, N. (2000). Ata as a Teaching Philosophy. Conference Paper, NZARE; New Plymouth, NZ
[19] Giovannelli, M (2007). Relationships between reflective disposition toward teaching and effective teaching. Journal of Educational Research, 96 (5) 293.

[20] Schon, D. (1987). Educating the reflective practitioner. San Francisco: Jossey-Bass.

[21] McEntee, G.H., Appleby, J., Dowd, J., Grant, J., Hole, S. \& Silva, P. (2003). At the heart teaching a guide to reflective practice. New York: Teachers College Press. 